\title{
Interpretation of Adsorption Thermodynamics and Kinetics
}

\author{
Augustus Newton Ebelegi, Nimibofa Ayawei*, Donbebe Wankasi \\ Department of Chemical Sciences, Niger Delta University, Wilberforce Island, Nigeria \\ Email: ${ }^{\star}$ ayawei4acad@gmail.com
}

How to cite this paper: Ebelegi, A.N., Ayawei, N. and Wankasi, D. (2020) Interpretation of Adsorption Thermodynamics and Kinetics. Open Journal of Physical Chemistry, 10, 166-182.

https://doi.org/10.4236/ojpc.2020.103010

Received: July 15, 2020

Accepted: August 21, 2020

Published: August 24, 2020

Copyright $\odot 2020$ by author(s) and Scientific Research Publishing Inc. This work is licensed under the Creative Commons Attribution-NonCommercial International License (CC BY-NC 4.0).

http://creativecommons.org/licenses/by-nc/4.0/

\begin{abstract}
A complete study of adsorption processes will be less complete if the structure and dynamics of its different elements and how they interact is not well captured. Therefore, the extensive study of adsorption thermodynamics in conjunction with adsorption kinetics is inevitable. Measurable thermodynamic properties such as temperature equilibrium constant and their non-measurable counterparts such as Gibbs free energy change, enthalpy, entropy etc. are very important design variables usually deployed for the evaluation and prediction of the mechanism of adsorption processes.
\end{abstract}

\section{Keywords}

Gibbs Free Energy, Entropy Change, Adsorption Density, Sticking Probability, Activation Energy, Pseudo-Second-Order Kinetic Model, Elovich Model, Brouers-Sotolongo Fractal Kinetic Model

\section{Introduction}

Although adsorption theory proposes a reduction in adsorption as temperature increases because adsorbates that were initially adsorbed on the surface of the adsorbent desorb at high temperatures [1], research reports have shown that different trends have been observed for porous, microporous and mesoporous adsorbents since higher temperatures facilitate the uptake of adsorbates into their pores and cavities [2] [3]. The effect of heat and time on the interaction between adsorbates and adsorbent surfaces during sorption processes is very important, because these interactions have been found to be temperature and time dependent [4] [5]. The experimental data obtained from adsorption processes monitored at different temperatures can be used to determine thermodynamic parameters such as free-energy change [6], enthalpy change [7], en- 
tropy change [8], activation energy [9], sticking probability [10], etc. Similarly, information obtained from adsorption experiments at different contact time(s) defines the kinetic behavior of adsorbates on adsorbents [11]. This paper is intended to give further insights to scholars, academics and students alike, easy tools that will facilitate a better understanding on interpretation and applications of experimental data using kinetic and thermodynamic models.

\section{Adsorption Thermodynamics}

Thermodynamic parameters of adsorption processes are easily evaluated because adsorption is a temperature dependent process [8]. Thermodynamic considerations for adsorption experiments are required in order to establish the spontaneity and feasibility of such processes. Therefore, experimental data obtained from adsorption procedures are employed to determine thermodynamic parameters such as Gibbs free energy change $\left(\Delta G^{0}\right)$, change in enthalpy $\left(\Delta H^{\dagger}\right)$, change in entropy $\left(\Delta S^{0}\right)$, Isosteric heat of adsorption $\left(\Delta H_{X}\right)$, adsorption potential $(A)$, hopping number $(n)$, sticking probability $\left(S^{\star}\right)$ adsorption density $(\rho)$ and activation energy $\left(E_{a}\right)$.

\subsection{Gibbs Free Energy of Change $\left(\Delta G^{0}\right)$}

Gibbs free energy of change is used to evaluate the spontaneity and feasibility of adsorption processes. A negative $\Delta G^{0}$ value validates a spontaneous process while a positive $\Delta G^{0}$ value is indicative of a non-spontaneous process as shown in Table 1.

The free energy change in an adsorption process is usually related to the equilibrium constant by the Gibbs fundamental equation [9].

Table 1. Thermodynamic parameters for adsorption of different pollutants onto some low cost adsorbents.

\begin{tabular}{|c|c|c|c|c|c|}
\hline Thermodynamic parameter & Adsorbent & Adsorbate & Value & Remark & Reference \\
\hline \multirow{3}{*}{$\begin{array}{c}\text { Gibbs free energy }\left(\Delta G^{0}\right) \\
\mathrm{kJ} \cdot \mathrm{mol}^{-1} \cdot \mathrm{K}^{-1}\end{array}$} & Bakers yeast & Nickel & -23.519 & Spontaneous & 10 \\
\hline & Pleurotuseryngii & Malachite green & $-10,388.3$ & Spontaneous & 11 \\
\hline & Coconut copra meal & Cadmium & -7.4 & Spontaneous & 12 \\
\hline \multirow{4}{*}{$\begin{array}{l}\text { Enthalpy change } \\
\left(\Delta H^{0}\right) \mathrm{kJ} \cdot \mathrm{mol}^{-1}\end{array}$} & Chemically modified rice husk & Malachite green & 63.76 & Endothermic & 13 \\
\hline & Mansonia wood & Basic dye & 67.1 & Endothermic & 14 \\
\hline & Wheat shell & Basic dye & 33.4 & Endothermic & 15 \\
\hline & Hematite & Cadmium & -13.09 & Exothermic & 16 \\
\hline \multirow{3}{*}{$\begin{array}{l}\text { Entropy change } \\
\left(\Delta S^{0}\right) \mathrm{J} \cdot \mathrm{mol}^{-1}\end{array}$} & Lateritic nickel Ore & Lead & 28.56 & chemisorption & 17 \\
\hline & Bentonite & Copper & 0.108 & chemisorption & 18 \\
\hline & Modified oak sawdust & Copper & 240 & chemisorption & 19 \\
\hline
\end{tabular}




$$
\Delta G^{0}=-R T \ln K_{C}
$$

where $R=$ Universal gas constant $\left(\mathrm{Jmol}^{-1} \cdot \mathrm{Kg}^{-1} \cdot \mathrm{K}^{-1}\right)$

$T=$ Temperature $(\mathrm{K})$

$K_{C}=$ Equilibrium constant.

This equation measures the changes in equilibrium constant with variations of temperature. Padmavathy reported the Biosorption of nickel (II) ions onto baker's yeast was a spontaneous and exothermic process [10]. Wu et al., also proved that the uptake of malachite green by a bio-sorbent Pleurotuseryngii was spontaneous [11]. In another report Y-S. Ho and A. E. Ofomaja showed that the biosorption of $\mathrm{Cd}^{2+}$ on coconut copra meal was feasible and spontaneous due to negative $\Delta G^{0}[12]$.

\subsection{Enthalpy Change $\left(\Delta H^{0}\right)$}

Change in enthalpy $\left(\Delta H^{0}\right)$ can be described as the energy supplied as heat at constant pressure when the system does no extra work. Enthalpy change is typically measured with a calorimeter by monitoring the temperature change that happens at constant pressure [12]. In adsorption study enthalpy change gives an insight into the nature and mechanism of adsorption processes and it is usually determined from the Van't Hoff equation [13].

$$
\log K_{C}=\frac{\Delta S^{0}}{2.303 R}-\frac{\Delta H}{2.303 R T}
$$

where $R=$ Universal gas constant $\left(\mathrm{J} \cdot \mathrm{mol}^{-1} \cdot \mathrm{K}^{-1}\right), T=$ Temperature $(\mathrm{K})$

$$
K_{C}(\text { Distribution coefficient })=\frac{C_{a}}{C_{e}}
$$

$C_{a}=$ Amount of adsorbate adsorbed at equilibrium $\left(\mathrm{mg} \cdot \mathrm{L}^{-1}\right)$

$C_{e}=$ Equilibrium concentration of adsorbate in solution $\left(\mathrm{mg} \cdot \mathrm{L}^{-1}\right)$.

A negative value of $\Delta H^{\dagger}$ implies an exothermic adsorption process while a positive $\Delta \mathrm{H}$ value is indicative of an endothermic process (see Table 1 ). In their report Chowdhury et al. showed that the positive value of $\Delta H^{\ominus}\left(89.13 \mathrm{KJ} \cdot \mathrm{mol}^{-1}\right)$ confirmed that the adsorption of malachite green onto chemically modified rice husk was endothermic [14]. Endothermic adsorption have also been reported for basic dye on mansonia wood $\left(67.1 \mathrm{KJ} \cdot \mathrm{mol}^{-1}\right)$ [15] and wheat shell (33.41 $\left.\mathrm{KJ} \cdot \mathrm{mol}^{-1}\right)[16]$.

\subsection{Entropy Change $\left(\Delta S^{0}\right)$}

A change in entropy during an adsorption process can be determined from the Vant' Hoff equation, where a positive $\Delta S$ shows the affinity of the adsorbent towards the adsorbate, it also suggests increased randomness at the solid/liquid interface with some structural changes in the adsorbent and adsorbate. Mohapatra et al. showed that $\Delta S^{0}$ was positive in their study on the kinetics and thermodynamics of $\mathrm{Pb}^{2+}$ adsorption onto lateritic nickel ores of Indian origin. This is typical of chemisorption [17]. In another research report Gupta, V. K. revealed a 
positive $\Delta S^{0}\left(0.108 \mathrm{~kJ} \cdot \mathrm{K}^{-1} \cdot \mathrm{mol}^{-1}\right)$ which reflects the affinity of Bentonite for copper (II) ions [18].

\subsection{Isosteric Heat of Adsorption $\left(\Delta H_{X}\right)$}

The Isosteric heat of adsorption is the ratio of the infinitesimal change in the adsorbate enthalpy to the infinitesimal change in the quantity adsorbed under constant temperature and pressure [16] heat of adsorption established at constant amount of adsorbate adsorbed. This parameter is essential in the characterization of adsorption processes and it is usually calculated using the ClausiusClaperyron Equation (4) [17].

$$
\frac{\mathrm{d}\left(\ln C_{e}\right)}{\mathrm{d} T}=-\frac{\Delta H_{X}}{R T^{2}}
$$

Chowdhury et al. observed that the Isosteric heat of adsorption $\left(\Delta H_{X}\right)$ for the adsorption of malachite green onto treated ice husk was chemisorption because Isosteric heat of adsorption $\left(\Delta H_{X}\right)$ obtained in their investigation was between 78 and $89 \mathrm{KJ} \cdot \mathrm{mol}^{-1}$ [19]. Isosteric heat of adsorption could also be used as a means of characterizing the surface of adsorbents since it has been proven that an adsorbent is homogeneous if its Isosteric heat of adsorption is independent of the amount of adsorbate it adsorbs and heterogeneous if it varies with the amount of adsorbate adsorbed [16]. This parameter also has a direct influence on hydrogen storage capacity of Metal Organic Frameworks (MOFs), Bae, -S and Snurr, R. Q. reported the optimal Isosteric heat of adsorption for hydrogen storage and delivery using MOFs. Their investigation showed that increasing Isosteric heat of adsorption for MOFs with large surface area results in higher hydrogen storage capacity [18].

\subsection{Hopping Number (n)}

The Hopping number describes the number of hopping done by the adsorbate molecule while finding a vacant site on the adsorbent surface during sorption processes [20]. The expression relating the hopping number (n) to the surface coverage is given as;

$$
n=\frac{1}{(1-\theta) \theta}
$$

The hopping number $(n)$ can be used to describe how fast an adsorption process happens, thus the smaller the hopping number $(n)$ the faster the sorption process [20]. In their report Menkiti et al., observed that acid treated chrysophyllumalbidium biomass exhibited faster uptake of Solid and Dissolved Particles (SDP) than the salt treated chrysophyllumalbidium biomass because the former had a smaller hopping number than the latter [21].

\subsection{Adsorption Potential (A)}

Adsorption potential can be described as the chemical potential that occurs as an 
adsorbate molecule moves from solution to the surface of an adsorbent during an adsorption process [18]. This parameter can be used to calculate the capability of an adsorbent to adsorb adsorbate molecules at a fixed temperature. Adsorption potential (A) can be evaluated by using the following expression

$$
A=-R T \ln \frac{C_{o}}{C_{e}}
$$

$C_{o}$ and $C_{e}$ are initial and final concentration of the adsorbate solution $\left(\mathrm{mol} \cdot \mathrm{mg}^{-1}\right)$, $R=$ universal gas constant $\left(\mathrm{KJ} \cdot \mathrm{mol}^{-1} \cdot \mathrm{K}^{-1}\right)$ and $T=$ absolute temperature at which the sorption occurred. This parameter has been utilized to add value to data obtained from adsorption experiments using modified biomass as adsorbent [21] [22] [23]

\subsection{Adsorption Density $(\rho)$}

Adsorption density is a parameter used for the evaluation of the packing of adsorbates on the surface of an adsorbent. It is usually analyzed at a fixed temperature [19]. The value of adsorption density $(\rho)$ of an adsorption process can be obtained using the following expression;

$$
\rho=Z_{r} C_{e} \exp -\left[\frac{\Delta G^{0}}{R T}\right]
$$

where;

$$
\begin{aligned}
& \rho=\text { adsorption density } \\
& Z=\text { valency of adsorbed ion } \\
& R=\text { effective radius of adsorbed ion } \\
& C_{e}=\text { equilibrium concentration of adsorbate solution }\left(\mathrm{mol} \cdot \mathrm{mg}^{-1}\right) \\
& R=\text { universal gas constant }\left(\mathrm{KJ} \cdot \mathrm{mol}^{-1} \cdot \mathrm{K}^{-1}\right) \\
& T=\text { absolute temperature }(\mathrm{K})
\end{aligned}
$$

Benjamin, M. M, used this parameter as the basis for comparing the multiple-site adsorption of $\mathrm{Cd}, \mathrm{Cu}, \mathrm{Zn}$ and $\mathrm{Pb}$ ions on amorphous iron Oxyhydroxide [24].

\subsection{Sticking Probability $\left(\mathrm{S}^{*}\right)$}

Sticking probability (sorption probability) is a parameter that shows the potential of an adsorbate to remain on an adsorbent indefinitely. It is a function of the adsorbate/adsorbent system and it serves the best purpose when its value lie between zero and unity $\left(0<\mathrm{S}^{*}<1\right)$ and it is independent of the system's operating temperature [25]. Sticking probability can be evaluated from the following equation:

$$
\ln (1-\theta)=\ln S^{*}+\frac{E_{a}}{R T}
$$

where; $\theta=$ surface coverage and $E_{a}=$ activation energy.

In their report Horsfall and Spiff showed how acid treatment enhanced the sticking probability of nickel ions on fluted pumpkin waste [20]. 


\subsection{Activation Energy $\left(E_{a}\right)$}

Activation energy is the minimum energy required to cause a chemical reaction. For sorption processes, a negative $E_{a}$ suggests a low temperature favours the process in which case the sorption process is termed to be exothermic [26] [27]. Conversely, a positive $E_{a}$ is an indication of the presence of an energy barrier in the sorption process which means the system requires energy (increased temperature) to drive the sorption process therefore such a sorption process is termed endothermic [23] [28]. The activation energy of adsorption processes can be estimated by the Arrhenius Equation (9) [23].

$$
\ln k_{2}=-\frac{E_{a}}{R T}+\ln k_{0}
$$

where $k_{0}=$ Arrhenius factor

A plot of $\ln k_{2}$ against $1 / T$ gives a straight line from which the activation energy $\left(E_{a}\right)$ can be evaluated (slope of the linear graph). Chowdhury et al. showed that the activation energy of the adsorption of malachite green on chemically modified rice husk was $68.1 \mathrm{~kJ} \cdot \mathrm{mol}^{-1}$ [19]. In another report Podder and Majumder reported the activation energy of $\mathrm{As}(\mathrm{III})$ and $\mathrm{As}(\mathrm{V})$ biosorption onto $\mathrm{TW} / \mathrm{MnFe}_{2} \mathrm{O}_{4}$ composite were 11.6 and $10.71 \mathrm{~kJ} \cdot \mathrm{mol}^{-1}$ [29]. These reports actually confirm the sorption processes to be endothermic.

\section{Adsorption Kinetics}

The kinetic behaviour of adsorbates on adsorbents has been studied using the effect of time on sorption. Due to the large collection of kinetic models the selection of suitable models for the analysis of sorption data is quite challenging. Scientific reports have shown how mathematical models were proposed and used to describe adsorption experiments [30] [31] [32] [33] [34]. Thus, adsorption kinetic models have been classified into two groups namely; adsorption reaction models and adsorption diffusion models. Adsorption reaction models reveal the rate of adsorbate uptake by adsorbents but they do not show the actual cause of adsorption. On the contrary adsorption diffusion models take into cognizance external diffusion, internal (pore) diffusion and effect of mass action (i.e. adsorption/desorption between adsorbates and active sites of adsorbents [35].

Pursuant to the aforementioned adsorption reaction models should be consistent with proposed mechanisms defined by fitting adsorption diffusion models.

\section{Adsorption Reaction Models}

\subsection{Pseudo-First-Order (Lagergren) Model}

The pseudo-first-order model is mostly used to analyze adsorption data obtained from the adsorption of adsorbates from aqueous solutions. It describes the rate of adsorption which is proportional to number of unoccupied binding sites on adsorbents [36]. This kinetic model is usually represented in the following equation [37]. 


$$
\log \left(q_{e}-e\right)=\log q_{e}\left(\frac{K_{1}}{2.303}\right) k
$$

Several researchers have employed this model to evaluate the rate of uptake of different adsorbates by specific adsorbents in aqueous media. Kazeem et al., reported a high correlation coefficient $\left(r^{2}=0.9778\right)$ using this model while investigating the removal of cationic dye from wastewater using aluminum activated carbon ad adsorbent [38]. In like manner Tran et al. investigated the uptake of Methylene green 5 by activated carbon using the pseudo-firs-order kinetic model $\left(r^{2}=0.37\right)$. The low correlation coefficient obtained is an indication that this model is not the best fit [39]. A high correlation coefficient $\left(r^{2}=0.989\right)$ was obtained by Fungaro et al. in their study of the removal of reactive orange 16 from wastewater using zeolite from cyclone ash [40]. Although the correlation coefficient was high, experimental data was best described by the pseudo-second-order kinetic model due to higher correlation coefficient.

\subsection{Pseudo-Second-Order Model}

The pseudo-second-order kinetic model describes the adsorption of adsorbates onto adsorbents where the chemical bonding (interaction) between adsorbates and functional groups on the surface of adsorbents are responsible for the adsorption capacity of adsorbent. It is based on equilibrium adsorption, which is dependent on the amount of adsorbate adsorbed onto the surface of an adsorbent and the amount of adsorbate adsorbed at equilibrium [41]. This model is used to predict the order of the sorption process, it also facilitates the evaluation of sorption capacity [42] [43]. The pseudo-second-order kinetic rate expression in the linearized form is shown in Equation (10).

$$
\frac{t}{q_{t}}=\frac{1}{K_{2} q_{e}^{2}}+\frac{1}{q_{e}} t
$$

For this model to emerge the best fit for sorption data a plot of $t / q_{t}$ against $t$ should show a linear connection, from which the amount of adsorbate adsorbed at equilibrium $\left(q_{e}, \mathrm{mg} / \mathrm{g}\right)$ and the equilibrium rate constant of pseudo-secondorder sorption $\left(K_{2}, \mathrm{~g} / \mathrm{mg} \mathrm{min}\right)$ can be evaluated from the slope and intercept respectively [44]. The pseudo-second-order kinetic model has been applied successfully to determine chemisorption in several sorption systems. Crini et al. proved the removal of malachite green from aqueous media with a cyclodextrin-based adsorbent followed the pseudo-second-order kinetic model $\left(r^{2}=\right.$ 0.9998) [45]. In another research Gong et al. reported the sorption of basic dye onto phosphoric acid esterified soya bean hull was best described by this model $\left(r^{2}=0.999\right)$ [46]. Similar reports have been published by Tsai et al. [47] and Santhi et al. [48].

\subsection{Elovich Model}

This model is used to describe adsorption processes that follow second-order kinetics with the assumption that the surface of the adsorbent is energetically 
heterogeneous in nature as such they show evidence of different activation energies [49] [50]. It has been extensively applied in the elucidation of chemisorption processes [51].

The Elovich model is represented by the following expression

$$
q_{t}=\frac{\ln (\alpha \beta)}{\beta}+\frac{\ln t}{\beta}
$$

where;

$$
\begin{aligned}
& q_{t}=\text { adsorption capacity at time } \mathrm{t}\left(\mathrm{mg} \cdot \mathrm{g}^{-1}\right) \\
& \alpha=\text { Initial adsorbate adsorption rate }\left(\mathrm{mg} \cdot \mathrm{g}^{-1} \cdot \mathrm{min}^{-1}\right) \\
& \beta=\text { Adsorption constant }\left(\mathrm{mg} \cdot \mathrm{g}^{-1} \cdot \mathrm{min}^{-1}\right)
\end{aligned}
$$

Initial adsorption rate $(\alpha)$ and adsorption constant $(\beta)$ can be evaluated from a linear plot of $q_{t}$ versus $\ln t$.

Hussien et al. utilized this model to analyze adsorption data obtained from the of adsorption process using spent-FCC catalyst and their report confirmed that the adsorption process is chemisorption [52]. Wu et al. showed the Elovich kinetic model was the most suitable kinetic model for describing the adsorption kinetics in dye-Chitosan systems [53]. Juan and Chen also established that the sorption of $\mathrm{Fe}^{3+}, \mathrm{Co}^{2+}, \mathrm{Ni}^{2+}, \mathrm{Cu}^{2+}$ and $\mathrm{Zn}^{2+}$ by solvent-impregnated resins as best described by the Elovich equation [54]. Other similar investigations have been reported [55] [56] [57] [58] [59].

\subsection{Brouers-Sotolongo Fractal Kinetic Model}

This model was developed specially to address sorption processes that occur at the solid-liquid interface of nanomaterials which usually present unique environments such as heterogeneous surfaces and complex reactions [60]. Reports have it that adsorbents made of nanomaterials have boundaries that separate mass and pore spaces (fractal surfaces) [61]. The fractality of nanomaterials could have arisen from the well defined pore network built up during synthesis and post synthesis processes, thus fractality is a foreseeable feature that can influence the adsorptive properties of adsorbents. The complex nature of adsorption on nanomaterials and its effects on kinetics are not often taken into account as such they are mostly illustrated using classical kinetic equations [62].

The fractal differential equation is given as;

$$
-\frac{\mathrm{d} q_{(t)}}{\mathrm{d} t^{a}}=k_{a, n} q_{(t)}^{n}
$$

where

$q_{(t)}=$ mass of adsorbate adsorbed per mass of adsorbent at time $\mathrm{t}$,

$n=$ apparent reaction order

$a=$ global fractal time index due to supposed fractal diffusion and sorption kinetics arising from geometric and energetic heterogeneity of adsorbent.

If particular values are assigned to the apparent reaction order (n) and global fractal time index (a) Equation (13) then corresponds to pseudo-first-order kinetics $(n=1, a=1)$, pseudo-second-order kinetics $(n=2, a=1)$, Weibull kinet- 
ics or Avrami kinetics $(n \neq 1, a=1)$ and Hill kinetics or fractal second-orderkinetics $(n=2, a \neq 1)[63]$.

Pseudo-first-order kinetic and pseudo-second-order kinetic models have been previously discussed (sections 3.1 and 3.2), thus the Weibull kinetic model can be represented with the following expression;

$$
q_{(t)}=q_{m}\left(1-\exp (t / \tau)^{a}\right)
$$

where,

$$
\tau_{50 \%}=\tau(\ln 2)^{1 / a}
$$

$\tau_{50 \%}$ represents the time required to adsorb one-half of the maximum adsorbed quantity.

The Hill kinetics model is expressed as follows;

$$
q_{t}=q_{m}\left(\frac{(t / \tau)^{a}}{1+(t / \tau)^{a}}\right)
$$

where, $\tau=\left(k_{2}, a q_{m}\right)^{-1 / a}$ and $\tau_{50 \%}=\tau$

Hamissa et al., reported the modeling of Methylene blue sorption onto Agave Americana fibre using fractal kinetics, the study showed that Methylene blue sorption were satisfactorily fitted by the Brouers-Sotolongo kinetic model with no systematic variation of the global fractal time index (a) which varies in the limits 0.6 - 0.9 [64]. In another study Al-Musawi et al., reported the modeling of kinetic data obtained from the adsorption of two antibiotics onto three nanoadsorbents using the Brouers-Sotolongo fractal equation [60].

\section{Adsorption Diffusion Models}

\subsection{Boyd Model}

This model predicts the rate determining step (slow step) involved in the adsorption process. The Boyd kinetic model is represented by the following expression [65];

$$
B_{t}=-0.4978-\ln \left(1-\frac{q}{q_{\infty}}\right)
$$

where;

$$
\begin{aligned}
& q=\text { Amount of adsorbate adsorbed at time } t\left(\mathrm{mg} \cdot \mathrm{g}^{-1}\right) \\
& q_{\infty}=\text { Amount of adsorbate adsorbed }\left(\mathrm{mg} \cdot \mathrm{g}^{-1}\right)
\end{aligned}
$$

Meng, F. W., applied this model for the study of phenol adsorption by a polymeric adsorbent (NDA-100) [66]. Nethaji et al., used this model to prove that external mass transfer is the rate determining step for the adsorption of cationic and anionic dyes onto carbonaceous particles prepared from Juglansregia shell biomass [44].

\subsection{Intra-Particle Diffusion Model}

Webber-Morris observed that in most adsorption processes the uptake of ad- 
sorbates varies proportionally with the square root of time $\left(t^{1 / 2}\right)$ [66]. The linearized form of this model is given as [67];

$$
q_{t}=K_{\mathrm{IPD}} t^{1 / 2}+C
$$

where;

$$
\begin{aligned}
& K_{\mathrm{IPD}}=\text { Intra-particle diffusion constant }\left(\mathrm{mg} \cdot \mathrm{g}^{-} \mathrm{min}^{1 / 2}\right) \\
& C=\text { Thickness of boundary layer (intercept). }
\end{aligned}
$$

When intra-particle diffusion alone is the rate determining step then a plot of $q_{t}$ vs $t^{1 / 2}$ appears as a linear graph that passes through the origin. However, if film diffusion also takes place simultaneously then the intercept " $\mathrm{C}$ " gives a clue on the thickness of the boundary layer [63]. Wang et al explored the kinetics of nitrate adsorption onto modified wheat residues and their results showed that the intra-particle diffusion model generated the best agreement with experimental data, which means intra-particle diffusion was the main rate determining step during the sorption process [64]. Similarly, Baduzzman et al. evaluated the removal of arsenic in aqueous solution using Ganular Ferric Hydroxide (GFH) and their results showed that intra-particle diffusion in an important mass transport process in the removal of arsenic using packed-bed treatment systems [65]. Several researchers have used this model to show that sorption processes they investigated were not only controlled by intraparticle diffusion but that film diffusion also played a role [66]-[71].

\subsection{Model Performance Indicators}

The linear forms of kinetic models discussed here are usually employed to plot graphs from which associated parameters are determined (intercepts and slopes). Thus the models are usually subjected to accuracy tests using model performance indicators (error functions) such as coefficient of determination $\left(R^{2}\right)$ and Chi square $\left(x^{2}\right)$, all in a bid to determine the model that fits the experimental data best.

\subsection{Coefficient of Determination $\left(R^{2}\right)$}

The coefficient of determination represents the variance about the mean, it is used to analyze the fitting degrees of kinetic models with experimental data [27] [39] [72] [73] [74]. The coefficient of determination $\left(R^{2}\right)$ is defined by the following equation [75].

$$
R^{2}=\frac{\sum\left(q_{e c a l}-q_{m \exp }\right)^{2}}{\sum\left(q_{e c a l}-q_{m \exp }\right)^{2}+\left(q_{c a l}-q_{m \exp }\right)^{2}}
$$

where

$q_{\text {exp }}=$ amount of adsorbate adsorbed by adsorbent during the experiment $\left(\mathrm{mg} \cdot \mathrm{g}^{-1}\right)$

$q_{c a l}=$ amount of adsorbate obtained by kinetic isotherm models $\left(\mathrm{mg} \cdot \mathrm{g}^{-1}\right)$

$q_{m \operatorname{mexp}}=$ average of $q_{\text {exp }}\left(\mathrm{mg}_{\mathrm{g}} \mathrm{g}^{-1}\right)$

Moussavi et al., applied this model as a criteria of goodness of fitness. Their 
results showed that the coefficient of determination $\left(R^{2}\right)$ for the pseudo-secondorder kinetic (PSO) is higher than that for pseudo-first-order kinetic (PFO) for the adsorption of all tested concentrations of amoxicillin onto ammonium chloride induced activated carbon (NAC) and standard activated carbon (SAC) is an indication that the kinetic data were best described with the pseudo-second-order kinetic model [76]. Similarly, Velinov et al. used the coefficient of determination as the basis for evaluation the best fit kinetic model for the Biosorption of loperamide by lignocellulosic- $\mathrm{Al}_{2} \mathrm{O}_{3}$ hybrid. The obtained result showed that the pseudo-second-order fitted better than the pseudo-first-order model because of higher coefficient of correlation [77].

\subsection{Chi-Square Test $\left(x^{2}\right)$}

This function is very important in the determination of the best fit for experimental data obtained from sorption procedures. It can be obtained by judging the sum square difference between experimental and calculated data, with each square difference divided by its corresponding values [78]. The value of this function can be evaluated from the following expression;

$$
\sum_{i=1}^{n} \frac{\left(q_{\text {ecal }}-q_{\text {emeas }}\right)^{2}}{q_{\text {emeas }}}
$$

Elbardiji et al., evaluated the predictive performance of the modified f-mexp equation for the modeling of adsorption kinetics of experimental systems using chi square $\left(x^{2}\right)$, and results revealed that the $\mathrm{f}$-mexp equation can fit the experimental data very well over the whole adsorption range [79]. Podder and Majumder also used this model to evaluate the goodness of fitness of adsorption kinetic data for $\mathrm{As}(\mathrm{III})$ and $\mathrm{As}(\mathrm{V})$ on $\mathrm{MnFe}_{2} \mathrm{O}_{4}$ composite [29].

\section{Conclusion}

In this review, we have discussed several thermodynamic and kinetic parameters with respect to how they impinge on adsorption processes. Thermodynamic parameters described herein are essential in determining the effect of heat on adsorption procedures and ultimately they help to define the spontaneity of adsorption processes. On the other hand, kinetic models were discussed under two basic categories namely: adsorption reaction models which in most instances define the rate at which adsorption takes place without providing exact insights into the mechanism of adsorption. Conversely, adsorption diffusion models describe basic steps that envisage mechanisms of adsorption processes.

\section{Conflicts of Interest}

The authors declare no conflicts of interest regarding the publication of this paper.

\section{References}

[1] Dabrowsky, A. (2001) Adsorption-From Theory to Practice. Advances in Colloids 
and Interface Science, 93, 135-224. https://doi.org/10.1016/S0001-8686(00)00082-8

[2] Inglezakis, V.J. and Zorpas, A.A. (2012) Heat of Adsorption, Adsorption Energy and Activation Energy in Adsorption and Ion Exchange Systems. Desalination and Water Treatment, 39, 149-157. https://doi.org/10.1080/19443994.2012.669169

[3] Hong, S., Wen, C., He, J., Gan, F. and Ho, Y.-S. (2009) Adsorption Thermodynamics of Methylene Blue onto Bentonite. Journal of Hazardous Materials, 167, 630-633. https://doi.org/10.1016/j.jhazmat.2009.01.014

[4] Anirudhan, T.-S. and Radharishnan, P.G. (2008) Thermodynamics and Kinetics of Adsorption of $\mathrm{Cu}$ (II) from Aqueous Solutions onto a New Cation Exchanger Derived from Tamarind Fruit Shell. The Journal of Chemical Thermodynamics, 40, 702-709. https://doi.org/10.1016/j.jct.2007.10.005

[5] Ho, Y.-S., Chiang, T.H. and Hsueh, Y.M. (2005) Removal of Basic Dye from Aqueous Solution Using Tree Fern as Adsorbent. Process Biochemistry, 40, 119-124.

[6] Liy, Y. and Liu, Y.J. (2008) Biosorption Isotherms, Kinetics and Thermodynamics. Separation and Purification Technology, 61, 229-242.

https://doi.org/10.1016/j.seppur.2007.10.002

[7] Saha, P. and Cowdhury, S. (2011) Insights into Adsorption Thermodynamics. http://www.intechopen.com/books/Thermodynamics/insight-into-adsorption-Ther $\underline{\text { modynamics }}$

[8] Thaligari, S.K., Srivastava, V.C. and Prasad, B. (2016) Adsorptive Desulfurization by Zinc-Impregnated Activated Carbon: Characterization, Kinetics, Isotherms, and Thermodynamic Modeling. Clean Technologies and Environmental Policy, 18, 1021-1030. https://doi.org/10.1007/s10098-015-1090-y

[9] Ebelegi, N.A. (2019) Surface Functionalization of Polyamidoamine Dendrimer for Sorption Studies. Niger Delta University, Bayelsa, Nigeria, 162.

[10] Padmavathy, V. (2008) Biosorption of Nickel(II) Ions by Baker's Yeast: Kinetic, Thermodynamic and Desorption Studies. Bioresource Technology, 99, 3100-3109. https://doi.org/10.1016/j.biortech.2007.05.070

[11] Ho, Y.-S. and Ofomaja, A.E. (2006) Biosorption Thermodynamics of Cadmium on Coconut Copra Meal as Biosorbent. Biochemical Engineering Journal, 30, 117-123. https://doi.org/10.1016/j.bej.2006.02.012

[12] Wu, J., Xia, A., Chen, C., Feng, L., Su, X. and Wang, X. (2019) Adsorption Thermodynamics and Dynamics of Three Typical Dyes onto Bio-Adsorbent Spent Substrate of Pleurotus eryngii. International Journal of Environmental Research and Public Health, 16, 2-11. https://doi.org/10.3390/ijerph16050679

[13] Atkins, P.W. and Paula, J.D. (2009) Physical Chemistry. 8th Edition, Oxford University Press, Oxford.

[14] Ofomaja, A.E. and Ho, Y.S. (2008) Effect of Temperatures and pH on Methyl Violet Biosoption by Mansonia Wood Sawdust. Bioresource Technology, 99, 5411-5417.

[15] Bulut, Y. and Aydin, H. (2006) A Kinetic and Thermodynamic Stud of Methylene Blue Adsorption on Wheat Shells. Desalination, 194, 259-267. https://doi.org/10.1016/j.desal.2005.10.032

[16] Bae, Y.-S. and Snurr, R.Q. (2010) Optimal Isosteric Heat of Adsorption for Hydrogen Storage and Deliver Using Metal-Organic Frameworks. Microporous and Mesoporous Materials, 132, 300-303. https://doi.org/10.1016/j.micromeso.2010.02.023

[17] Gupta, V.K. (1998) Equilibrium Uptake, Sorption Dynamics, Process Development and Column Operations for the Removal of Copper and Nickel from Aqueous Solu- 
tion and Wastewater Using Activated Slag, a Low-Cost Adsorbent. Industrial \& Engineering Chemistry Research, 37, 192-202. https://doi.org/10.1021/ie9703898

[18] Chowdhury, S., Mishra, R., Saha, P. and Kushwaha, P. (2011) Adsorption Thermodynamics, Kinetics and Isosteric Heat of Adsorption of Malachite Green onto Chemically Modified Rice Husk. Desalination, 265, 159-168. https://doi.org/10.1016/j.desal.2010.07.047

[19] Horsfall, M. and Spiff, I.A. (2005) Effect of 2-Mercaptoethanoic Acid Treatment of Fluted Pumpkin Waste (Telfairia occidentalis Hook. F.) on the Sorption of $\mathrm{Ni}^{2+}$ Ions from Aqueous Solutions. Journal of Scientific and Industrial Research, 64, 613-620.

[20] Menkiti, M.C., Aneke, M.C., Ejikeme, P.M., Onukwuli, O.D. and Menkiti, N.U. (2014) Adsorptive Treatment of Brewery Effluent Using Activated Chrysophyllum albidum Seed Shell Carbon. SpringerPlus, 3, Article No. 213. https://doi.org/10.1186/2193-1801-3-213

[21] Meena, A.K., Kadirvelu, K. and Mishra, G.K. (2008) Adsorption Removal of Heavy Metals from Aqueous Solution by Treated Sawdust (Acacia arabica). Journal of Scientific and Industrial Research, 150, 604-611. https://doi.org/10.1016/j.jhazmat.2007.05.030

[22] Mahapatra, M., Khatun, S. and Anand, S. (2009) Kinetics and Thermodynamics of Lead (II) Adsorption onto Lateritic Nickel Ores of Indian Origin. Chemical Engineering Journal, 155, 184-190. https://doi.org/10.1016/j.cej.2009.07.035

[23] Benjamin, M.M. (1981) Multiple-Site Adsorption of Cd, Cu, Zn and Pb on Amorphous Iron Oxyhydroxide. Journal of Colloid and Interface Science, 79, 209-221. https://doi.org/10.1016/0021-9797(81)90063-1

[24] Higachi, K., Ito H. and Oishi, J. (1984) Principles of Adsorption and Adsorption Processes. John Wiley and Sons, New York, 71-73.

[25] Asku, Z. (2001) Equilibrium and Kinetic Modeling of Cadmium(II) Biosorption B C. vulgaris in a Batch System: Effect of Temperature. Separation and Purification Technology, 21, 285-295. https://doi.org/10.1016/S1383-5866(00)00212-4

[26] Asku, Z. and Tezer, S. (2005) Biosorption of Reactive Dyes on the Green Algae Chlorella vulgaris. Process Biochemistry, 40, 1347-1361. https://doi.org/10.1016/j.procbio.2004.06.007

[27] Yakout, S.M. and Elsherif, E. (2010) Batch Kinetics Isotherm and Thermodynamic Studies of Studies of Adsorption of Strontium from Aqueous Solution onto Low Cost Rice-Straw Based Carbons. Carbon-Science and Technology, 3, 144-153.

[28] Podder, M.S. and Majumder, C.B. (2017) Biosorption of As(III) and As(V) on the Surface of TW/ $\mathrm{MnFeO}_{4}$ Composite from Wastewater: Kinetics, Mechanistic and Thermodynamics. Applied Water Science, 7, 2689-2715. https://doi.org/10.1007/s13201-016-0487-Z

[29] Bunat, F., Al-Asheh, S. and Makhadmeh, L. (2003) Preparation and Examination of Activated Carbons from Date Pits Impregnated with Potassium Hydroxide for the Removal of Methylene Blue from Aqueous Solutions. Adsorption Science \& Technology, 21, 597-606. https://doi.org/10.1260/026361703771953613

[30] Sun, Q.Y. and Yang, L.Z. (2003) The Adsorption of Basic Dyes from Aqueous Solution on Modified Peat-Resin Particle. Water Research, 37, 1535-1544. https://doi.org/10.1016/S0043-1354(02)00520-1

[31] Jain, A.K., Gupta, G.K., Jain, S. and Suhas (2004) Removal of Chrolophenols Using Industrial Wastes. Environmental Science \& Technology, 38, 1195-1200.

https://doi.org/10.1021/es034412u 
[32] Hameed, B.H. and El-Khaiary, M.I. (2008) Batch Removal of Malachite Green from Aqueous Solutions by Adsorption on Oil Palm Tree Trunk Fibre: Equilibrium Isotherms and Kinetic Studies. Journal of Hazardous Materials, 154, 237-244. https://doi.org/10.1016/j.jhazmat.2007.10.017

[33] Wan Ngah, W.S. and Hanafiah, M.A.K.M. (2008) Adsorption of Copperon Rubber (Hevea brasiliensis) Leave Powder: Kinetic, Equilibrium and Thermodynamic Studies. Biochemical Engineering Journal, 39, 521-530. https://doi.org/10.1016/j.bej.2007.11.006

[34] Mall, I.D., Srivastava, V.C., Agarwal, N.K. and Mishra, I.M. (2005) Removal of Congo Red from Aqueous Solution by Bagasse Fly Ash and Activated Carbon: Kinetic Study and Equilibrium Isotherm Analyses. Chemosphere, 6, 492-501. https://doi.org/10.1016/j.chemosphere.2005.03.065

[35] Lagergren, S. (1898) About the Theory of So-Called Adsorption of Soluble Substances. Kungliga Svenska Vetenskapsakademiens Handlingar, 24, 1-39.

[36] Hui, Q., Lu, L.V., Pan, B.-C., Zhang, Q.J., Zhang, W.-M. and Zhang, Q.-X. (2009) Critical Review of Adsorption Kinetic Models. Journal of Zhejiang University-Science $A, 10,716-724$. https://doi.org/10.1631/jzus.A0820524

[37] Kazeem, T.M., Lateef, S.A., Ganiyu, S.A., Qamaruddin, M., Tminu, A., Sulaiman, K.O., Jilani, S.M.S. and Ahooshani, K. (2018) Aluminum-Modified Activated Carbon as Efficient Adsorbent for Cleaning Cationic Dye in Wastewater. Journal of Cleaner Production, 205, 303-312. https://doi.org/10.1016/j.jclepro.2018.09.114

[38] Trans, H.N., You, S. and Chao, H.-P. (2018) Fast and Efficient Adsorption of Methylene Green 5 in Activated Carbon Prepared from Ne Chemical Activation $\mathrm{Me}$ thod. Journal of Environmental Management, 188, 322-336. https://doi.org/10.1016/j.jenvman.2016.12.003

[39] Fungaro, D.A., Borrely, S.I. and Carvalho, T.E.M. (2013) Surfactant Modified Zeolite from Cyclone Ash as Adsorbent for Removal of Reactive Orange 16 from Aqueous Solution. American Journal of Environmental Protection, 1, 1-9. https://doi.org/10.12691/env-1-1-1

[40] Ho, Y.S. and Mckay, G. (1998) A Comparison of Chemisorption Kinetic Models Applied to Pollutant Removal on Various Sorbents. Process Safety and Environmental Protection, 76, 332-340. https://doi.org/10.1205/095758298529696

[41] Ho, Y. (2006) Review of Second-Order Models for Adsorption Systems. Journal of Hazardous Materials, 136, 681-689. https://doi.org/10.1016/j.jhazmat.2005.12.043

[42] Wankasi, D. (2013) Adsorption a Guide to Experimental Data Analysis. Ano Publication Company, Port Harcourt, Rivers State.

[43] Nethaji, S., Sivasamy, A. and Mandal, A.B. (2013) Adsorption Isotherms, Kinetics and Mechanism for the Adsorption of Cationic and Anionic Dyes onto Carbonaceous Particles Prepared from Julans regia Shell Biomass. International Journal of Environmental Science and Technology, 10, 231-242. https://doi.org/10.1007/s13762-012-0112-0

[44] Crini, G., Peindy, H., Gimbert, F. and Robert, C. (2007) Removal of C.I. Basic Green 4 (Malachite Green) from Aqueous Solutions by Adsorption Using Cyclodextrin-Based Adsorbent: Kinetic and Equilibrium Studies. Separation and Purification Technology, 53, 97-110. https://doi.org/10.1016/j.seppur.2006.06.018

[45] Gong, R., Sun, J., Zhang, D., Zhong, K. and Zhu, G. (2008) Kinetics and Thermodynamics of Basic Dye Sorption on Phosphoric Acid Esterifying Soybean Hull with Solid Phase Preparation Technique. Bioresource Technology, 99, 4510-4514. https://doi.org/10.1016/j.biortech.2007.08.061 
[46] Tsai, W.-T. and Chen, H.-R. (2010) Removal of Malachite Green from Aqueous Solution Using Low-Cost Chlorella-Based Biomass. Journal of Hazardous Materials, 175, 844-849. https://doi.org/10.1016/j.jhazmat.2009.10.087

[47] Santhi, T., Manonmani, S. and Smitha, T. (2010) Removal of Malachite Green from Aqueous Solution by Activated Carbon Prepared from the Epicarp of Ricinus communis by Adsorption. Journal of Hazardous Materials, 179, 178-186. https://doi.org/10.1016/j.jhazmat.2010.02.076

[48] Low, M.J.D. (1960) Kinetics of Chemisorption of Gases on Solids. Chemical Reviews, 60, 267-312.

[49] Peres Marin, A.B., Aguilar, M.I., Meseguer, V.F., Ortuno, J.F., Saez, J. and Llorens, M. (2009) Biosorption of Chromium (III) by Orange (Citrus cinensis) Waste: Batch and Continuous Studies. Chemical Engineering Journal, 155, 199-206. https://doi.org/10.1016/j.cej.2009.07.034

[50] Wankasi, D. and Dikio, E.D. (2014) Polyvinyl Chloride Waste as an Adsorbent for the Sorption of $\mathrm{pb}^{2+}$ from Aqueous Solution. Journal of Chemistry, 2014, Article ID: 817527. https://doi.org/10.1155/2014/817527

[51] Hussein, Z., Kumar, R. and Meghavatu, D. (2018) Kinetics and Thermodynamics of Adsorption Process Using a Spent-FCC Catalyst. International Journal of Engineering \& Technology, 7, 84-287. https://doi.org/10.14419/ijet.v7i4.5.20090

[52] Chien, S.H. and Clayton, W.R. (1980) Application of Elovich Equation to the Kinetics of Phosphate Release and Sorption on Soils. Soil Science Society of America Journal, 44, 256-268.

https://doi.org/10.2136/sssaj1980.03615995004400020013x

[53] Bhattacharya, A.K. and Venkobachar, C. (1984) Removal of Cadmium (II) by Low Cost Adsorbents. Journal of Environmental Engineering, 110, 110-122. https://doi.org/10.1061/(ASCE)0733-9372(1984)110:1(110)

[54] Juan, R.-S. and Chen, M-L. (1997) Application of the Elovich Equation to the Kinetics off Metal Sorption with Solvent-Impregnated Resins. Industrial \& Engineering Chemistry Research, 36, 813-820. https://doi.org/10.1021/ie960351f

[55] Cheung, C.W., Porter, J.F. and Mckay, G. (2001) Sorption Kinetic Analysis for the Removal of Cadmium Ions from Effluents Using Bone Char. Water Research, 35, 605-612. https://doi.org/10.1016/S0043-1354(00)00306-7

[56] Heimberg, J.A., Wahl, K.J., Singer, I.I. and Erdemir, A. (2001) Superlow Friction Behavior of Diamond-Like Carbon Coatings: Time and Speed Effects. Applied Physics Letters, 79, 2449-2451. https://doi.org/10.1063/1.1366649

[57] Rudzinski, W. and Panczyk, T. (2000) Kinetics of Isothermal Adsorption on Energetically Heterogeneous Surfaces: A New theoretical Description Based on the Statistically Rate of Interfacial Transport. The Journal of Physical Chemistry B, 104, 9149-9162. https://doi.org/10.1021/jp000045m

[58] Sag, Y. and Aktay, Y. (2002) Kinetic Studies on Sorption of $\mathrm{Cr}(\mathrm{VI})$ and $\mathrm{Cu}(\mathrm{II})$ Ions by Chitin, Chitosan and Rhyzopus arrhizus. Biochemical Engineering Journal, 12, 143-153. https://doi.org/10.1016/S1369-703X(02)00068-2

[59] Zeldowitsch, J. (1934) On the Mechanism of Catalytic Oxidation of CO Band $\mathrm{MnO}_{2}$. Acta Physicochimica URSS, 1, 364-449.

[60] Al-Musawi, T.J., Brouers, F. and Zarrabi, M. (2016) Kinetic Modeling of Antibiotic Adsorption onto Different Nanomaterials Using the Brouers-Sotolongo Fractal Equation. Environmental Science and Pollution Research, 24, 4048-4057.

https://doi.org/10.1007/s11356-016-8182-Z 
[61] Gaspard, S., Altenor, S., Passe-Coutrin, N. and Ouensanga, A. and Brouers, F. (2006) Parameters for a New Kinetic Equation to Evaluate Activated Carbon Efficiency for Water Treatment. Water Research, 40, 3467-3477. https://doi.org/10.1007/s11356-016-8182-Z

[62] Do, D.D. and Wang, K. (1998) Dual Diffusion and Finite Mass Exchange Model for Adsorption Kinetics Inactivated Carbon. AlChE Journal, 44, 68-82. https://doi.org/10.1002/aic.690440109

[63] Brouers, F. (2014) The Fractal (BSF) Kinetics Equation and Its Approximations. Journal of Modern Physics, 5, 1594-1601. https://doi.org/10.4236/jmp.2014.516160

[64] Wang, Y., Gao, B.-Y., Yue, W.-W. and Yue, Q.-Y. (2007) Adsorption Kinetics of Nirates from Aqueous Solutions onto Modified Wheat Residue. Colloids and Surfaces A: Physicochemical and Engineering Aspects, 308, 1-5. https://doi.org/10.1016/j.colsurfa.2007.05.014

[65] Badruzzman, M., Westerhoff, P. and Knappe, D.R.U. (2004) Intra Particle Diffusion and Adsorption of Arsenate onto Granular Ferric Hydroxide (GFH). Water Research, 38, 4002-4012.

[66] Ben Hamissa, A.M., Brouers, F., Ncibi, M.C. and Seffen, M. (2014) Kinetic Modeling on Methylene Blue Sorption onto Agave americana Fibers: Fractal Kinetics and Regeneration Studies. Separation Science and Technology, 48, 2834-2842. https://doi.org/10.1080/01496395.2013.809104

[67] Vadivelan, V. and Vasanth, K.K. (2005) Equilibrium, Kinetics, Mechanism, and Process Design for the Sorption of Methylene Blue onto Rice Husk. Journal of Colloid and Interface Science, 286, 90-100. https://doi.org/10.1016/j.jcis.2005.01.007

[68] Meng, F.W. (2005) Study on a Mathematical Model in Predicting Breakthrough Curves of Fixed-Bed Adsorption onto Resin Adsorbent. MS Thesis, Nanjing University, Nanjing, 28-36.

[69] Horsfall, M. and Spiff, A. (2005) Effects of Temperature on the Sorption of $\mathrm{Pb}^{2+}$ and $\mathrm{Cd}^{2+}$ from Aqueous Solution by Caladium bicolor (Wild Cocoyam) Biomass. Electronic Journal of Biotechnology, 8, 162-168. https://doi.org/10.2225/vol8-issue2-fulltext-4

[70] Ahmad, M.A., Ahmad Puad, N.A. and Bello, O.S. (2014) Kinetic, Equilibrium and Thermodynamic Studies of Synthetic Dye Removal Using Pomegranate Peel Activated Carbon Prepared by Microwave-Induced $\mathrm{KOH}$ Activation. Water Resources and Industry, 6, 18-35. https://doi.org/10.1016/j.wri.2014.06.002

[71] Lazaridi, N.K. and Asouhidou, D.D. (2003) Kinetics of Sorptive Removal of Chromium(IV) from Aqueous Solutions by Calcined $\mathrm{Mg}-\mathrm{Al}-\mathrm{CO}_{3}$ Hydrotalcite. Water Research, 37, 2875-2882. https://doi.org/10.1016/S0043-1354(03)00119-2

[72] Alkan, M., Demibas, O. and Dogan, M. (2007) Adsorption Kinetics and Thermodynamics of an Anionic Dye onto Sapiolite. Microporous and Mesoporous Materials, 101, 388-396. https://doi.org/10.1016/j.micromeso.2006.12.007

[73] Weber, W.J. and Morris, J.C. (1962) Advances in Water Pollution Research: Removal of Biologically Resistant Pollutant from Wastewater by Adsorption. Proceedings of 1 st International Conference on Water Pollution Symposium, 2, 231-266.

[74] Elmorsi, T.M. (2011) Equilibrium Isotherms and Kinetic Studies of Removal of Methylene Blue Dye by Adsorption onto Miswak Leaves as a Natural Adsorbent. Journal of Environmental Protection, 2, 817-827. https://doi.org/10.4236/jep.2011.26093 
[75] Ho, V.S. (2006) Second-Order Kinetics Models for the Sorption of Cadmium on Tree Fern: A Comparison of Linear and Non-Linear Methods. Water Research, 40, 119-125. https://doi.org/10.1016/j.watres.2005.10.040

[76] Kumar, K.V., Pokordi, K. and Roch, F. (2008) Comparison of Various Error Functions in the Predicting the Optimum Isotherm by Linear and Non-Linear Regression Analysis for the Sorption of Basic Red 9 by Activated Carbon. Journal of Hazardous Materials, 150, 158-165. https://doi.org/10.1016/j.jhazmat.2007.09.020

[77] Moussavi, G., Alahabadi, A., Yaghmaeian, K. and Eskandari, M. (2013) Preparation, Characterization and Adsorption Potential of the $\mathrm{NH}_{4} \mathrm{Cl}$-Induced Activated Carbon for the Removal of Amoxicillin Antibiotic from Water. Chemical Engineering Journal, 17, 119-128. https://doi.org/10.1016/j.cej.2012.11.069

[78] Velinov, N., Najdanovic, S., Vucic, M.R., Mitrovic, J., Kostic, M., Bojic, D. and Bojic, A. (2019) Biosorption of Loperamide by Cellulosic- $\mathrm{Al}_{2} \mathrm{O}_{3}$ Hybrid: Optimization, Kinetic, Isothermal and Thermodynamic Studies. Cellulose Chemistry and Technology, 53, 175-189.

https://doi.org/10.35812/CelluloseChemTechnol.2019.53.19

[79] El Bardiji, N., Ziate, K., Naji, A. and Saidi, M. (2020) Fractal-Like Kinetics of Adsorption Applied to the Solid/Solution Interface. ACS Omega, 5, 5105-5115. https://doi.org/10.1021/acsomega.9b04088 